\title{
Multiple electrolyte disorders in a neurosurgical patient: solving the rebus
}

\author{
Valeria Corradetti ${ }^{1 \dagger}$, Pasquale Esposito $^{1 *}{ }^{*}$, Teresa Rampino $^{1}$, Marilena Gregorini ${ }^{1}$, Carmelo Libetta ${ }^{1}$, Francesca Bosio $^{1}$, \\ Teresa Valsania', Eleonora Francesca Pattonieri ${ }^{1}$, Chiara Rocca', Stefania Bianzina ${ }^{2}$ and Antonio Dal Canton ${ }^{1}$
}

\begin{abstract}
Background: It is important to ensure an adequate sodium and volume balance in neurosurgical patients in order to avoid the worsening of brain injury.

Indeed, hyponatremia and polyuria, that are frequent in this patient population, are potentially harmful, especially if not promptly recognized.

Differential diagnosis is often challenging, including disorders, which, in view of similar clinical pictures, present very different pathophysiological bases, such as syndrome of inappropriate antidiuresis, cerebral/renal salt wasting syndrome and diabetes insipidus.

Case presentation: Here we present the clinical report of a 67-year-old man with a recent episode of acute subarachnoid haemorrhage, admitted to our ward because of severe hyponatremia, hypokalemia and huge polyuria. We performed a complete workup to identify the underlying causes of these alterations and found a complex picture of salt wasting syndrome associated to primary polydipsia. The appropriate diagnosis allowed us to correct the patient hydro-electrolyte balance.
\end{abstract}

Conclusion: The comprehension of the pathophysiological mechanisms is essential to adequately recognize and treat hydro-electrolyte disorders, also solving the most complex clinical problems.

Keywords: Hyponatremia, Polyuria, Hypokalemia, Primary polydipsia, Salt wasting syndromes,

Subarachnoid haemorrhage

\section{Background}

An optimal balance of sodium and volume is of primary importance in brain-injured patients. In particular, changes in serum sodium concentration (mainly hyponatremia) influence neuronal size, while maintaining an adequate cerebral perfusion pressure avoids further injury [1].

Therefore, hyponatremia and polyuria could represent potentially severe conditions, especially if the underlying causes are not promptly recognized [2].

Differential diagnosis is often challenging, since it includes diseases, which, in view of similar clinical pictures, have very different pathophysiological bases, such as syndrome of inappropriate antidiuresis (SIAD),

\footnotetext{
* Correspondence: p.esposito@smatteo.pv.it

${ }^{\dagger}$ Equal contributors

'Unit of Nephrology, Dialysis and Transplantation, Fondazione IRCCS

Policlinico San Matteo and University of Pavia, Piazzale Golgi 19, 27100 Pavia,

Italy

Full list of author information is available at the end of the article
}

cerebral/renal salt wasting syndrome (C/RSWS) and diabetes insipidus (DI) [3].

Here we report a case of a neurosurgical patient who presented complex electrolyte disorders associated to marked polyuria.

\section{Case presentation}

A 67-year-old man was admitted in the Infectious Diseases Unit of our hospital because of pneumonia and urosepsis complicating a post-traumatic subarachnoid haemorrhage (SAH).

His past medical history consisted of hypertension, progressive supranuclear palsy-like Parkinsonism and recurrent moderate hypokalemia and slight hyponatremia. His home therapy included angiotensin receptor blockers, angiotensin converting enzyme inhibitors, aldosterone blockers, levodopa/carbidopa and sertraline.

At the admission the patient was febrile and asthenic; blood tests showed severe hyponatremia (Na $120 \mathrm{mEq} / \mathrm{l})$

\section{Biomed Central}


and hypokalemia (K $2.6 \mathrm{mEq} / \mathrm{l}$ ), neutrophil leucocytosis, normal liver and renal functions. Multiple antimicrobial therapies, including meropenem and levofloxacin, steroids, tetracosactide and $0.9 \% \mathrm{NaCl}$ saline infusions were promptly initiated.

In the following days the patient showed negative volume balance (about $-2.5 \mathrm{l} /$ day with a median diuresis of $7 \mathrm{l} /$ day), while the arterial blood analysis revealed severe metabolic alkalosis and hypokalemia $\left(\mathrm{pH}\right.$ 7.6, $\mathrm{HCO}_{3}$ $46 \mathrm{mEq}$, Base Excess $21 \mathrm{mEq} / \mathrm{l}, \mathrm{K} 1.5 \mathrm{mEq} / \mathrm{l})$. Simultaneously, his general conditions progressively worsened insomuch as he was transferred to the Intensive Care Unit.

There, the patient was treated with abundant infusions (3-4 1/day) of Ringer's acetate, $\mathrm{KCl}$ i.v. supplementation (60-80 mEq/day) and hypertonic solutions $(\mathrm{NaCl} 3 \%$ at a mean infusion rate of $20 \mathrm{ml} / \mathrm{h}$ ); blood exams showed $\mathrm{Na} 124-130 \mathrm{mEq} / \mathrm{l}, \mathrm{K} 2.3 \mathrm{mEq} / \mathrm{l}$ and progressive improvement of metabolic alkalosis.

Because of the persistent negative liquid balance $(-2 \mathrm{l} /$ day) and marked diuresis (6 l/day), insipidus diabetes was suspected and a NMR of the turcic sella was performed. This exam showed an absence of the normal hyperintensity of the neurohypophysis [Figure 1], consistent with the supposed diagnosis; consequently, therapy with desmopressin was started at dose of $2 \mu \mathrm{g} /$ day i.v. The general and hemodynamic conditions gradually improved, but fluid and electrolyte balance did not change despite desmopressin therapy.

Once stabilised, the patient was transferred to our ward, where he presented hypotension and severely dehydrated oral mucous membranes. With the intent of discerning the spontaneous electrolyte and liquid balance, we stopped desmopressin and steroids administration, beginning a controlled infusion of liquids and electrolytes.
After few days, since the patient still showed persistent polyuria with negative liquid balance $(-2 / 3 \mathrm{l}$, diuresis $6 \mathrm{l} /$ day), hypokalemia and metabolic alkalosis $(\mathrm{pH} 7.47$, $\mathrm{HCO}_{3} 30 \mathrm{mEq} / \mathrm{l}$ ) despite of $\mathrm{KCl}$ supplements, we decided to suspend infusions.

The plasmatic osmolarity values ranged from 245 to $292 \mathrm{mOsm} / \mathrm{l}$, urinary osmolarity (Uosm) showed extremely variable levels from 275 to $431 \mathrm{mOsm} / \mathrm{l}$, while ADH $(11,9 \mathrm{pg} / \mathrm{ml}$ with a normal range < 13), TSH, T4, ACTH and cortisol serum levels resulted normal. Moreover, ultrasonography was negative for renal artery stenosis, as well as for any cardiac alteration.

Our attention was then focused on the Uosm value, suggestive for a mixed diuresis composed of both water and solutes. Urine evaluations revealed a sodium chloride driven diuresis, as proven by the high concentrations of urinary sodium ( $\mathrm{Na}$ U $900 \mathrm{mEq} / 24 \mathrm{~h}$ with Urinary Anion Gap $40 \mathrm{mEq} / \mathrm{l}$ ) associated to low urinary glucose and urea levels. This urinary sodium loss was accompanied by an estimated total sodium deficit of about $600 \mathrm{mEq}$, calculated considering a patient weight of $70 \mathrm{Kg}$ - corresponding to total body water (TBW) of $42 \mathrm{Kg}$ - and an actual natremia of $120 \mathrm{mEq} / \mathrm{l}$ [4].

On the basis of these evaluations, together with the evidence of hypovolemia, we diagnosed a salt loosing nephropathy. However, the explanation of the free-water part of the diuresis was still difficult to find. In fact, the patient was no longer receiving i.v. infusions and was confined to bed, reporting to need help to eat and drink.

So, we excluded both iatrogenic excessive water administration and polydipsia.

Aiming to confirm the only missing diagnosis, i.e. diabetes insipidus, supported by NMR findings, we performed a water deprivation test. Surprisingly, we found a preserved urine concentrating capacity (Uosm was $222 \mathrm{mOsm} / \mathrm{l}$ at the beginning of the test and $556 \mathrm{mOsm} / \mathrm{l}$

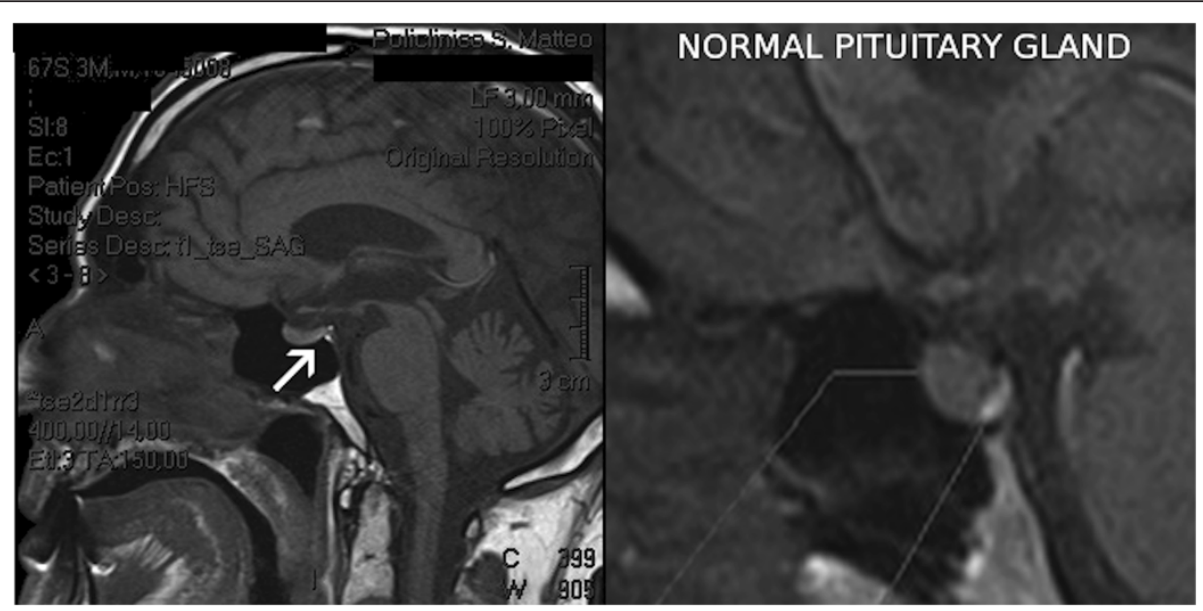

Figure 1 NMR imaging of the turcic sella: arrow shows the absence of the physiological hyper intensity of the neurohypophysis. 
at the end). During this test the patient complained of an irresistible desire of water and, unexpectedly, he revealed an ability to drink autonomously a large amount of liquids.

These findings suggested a diagnosis of primary polydipsia, further confirmed by the effectiveness of psychotherapy, which was associated to a rapid normalization of the volume balance [Figure 2].

Consequently, we prescribed a measured intake of water $(2000 \mathrm{ml} /$ day), sodium chloride $(19 \mathrm{~g} /$ day admi potassium and acid-base equilibrium and well-compensated hemodynamics.

Hence, it was possible to transfer the patient to a rehabilitative hospitalization. Ten months later the patient still presented good general conditions, controlled thirst and water intake, normal serum potassium and sodium levels with only a moderate sodium chloride supplementation (3 g/day).

\section{Conclusions}

The clinical picture of this patient showed the coexistence of many severe and difficult to interpret hydroelectrolyte disorders.

In a patient with a recent history of SAH, the differential diagnosis of hyponatremia comprises erroneous fluid administration, diuretic abuse, acute ACHT deficiency, SIAD, C/RSWS or a combination of these causes [5].

A pathophysiologic approach, considering the assessment of serum and urinary osmolality together with volume status and urinary sodium concentration, may be of help in guiding the diagnostic process (Table 1) [6].

In our case hormone dosing excluded the presence of ACTH deficiency.

Considering that diuretics or excessive amount of fluids were not administrated, the most probably diagnoses remained SIAD or C/RSWS, which differ mainly for the extracellular volume (ECV) status, normal in SIAD while reduced in C/RSWS [7].

SIAD is a disorder of sodium and water characterized by a normovolemic hyponatremia [8]. Since it is mainly a diagnosis of exclusion, all other causes of hyponatremia must be ruled out. The pathophysiological bases are an absolute increase in TBW and impaired urinary dilution ability in absence of any renal disease or stimuli to release ADH [9].

C/RSWS, instead, is a condition of extracellular volume depletion due to a renal sodium transport abnormality with or without high levels of urinary sodium, hyponatremia or cerebral disease [10]. Even if the pathophysiology of the disease is still not perfectly known, some authors hypothesized the presence of abnormal elevations in circulating natriuretic peptides $[11,12]$.

In case of diagnostic uncertainty between SIAD and C/RSWS, the rapid correction of hyponatremia with infusion of saline solutions suggests a diagnosis of hypovolemic hyponatremia [9]. In our case, the presence of hypotension and signs of dehydration, including metabolic alkalosis, together with the evidence of elevated urinary sodium content led us to hypothesize a salt wasting syndrome, which satisfactorily responded to the infusion therapy.

Of note, another factor that potentially contributed to the pathogenesis of hyponatremia was treatment with sertraline, an antidepressant of the selective serotonin reuptake inhibitor (SSRI) class, which use has been already related to hyponatremia, through the development of SIAD [13]. However, since sertraline was stopped soon after the admission, it is unlikely that this drug played a role in the subsequent hydro-electrolyte alterations.

Severe hypokalemia, persistent despite a massive i.v. supplementation, was an additional life-threatening

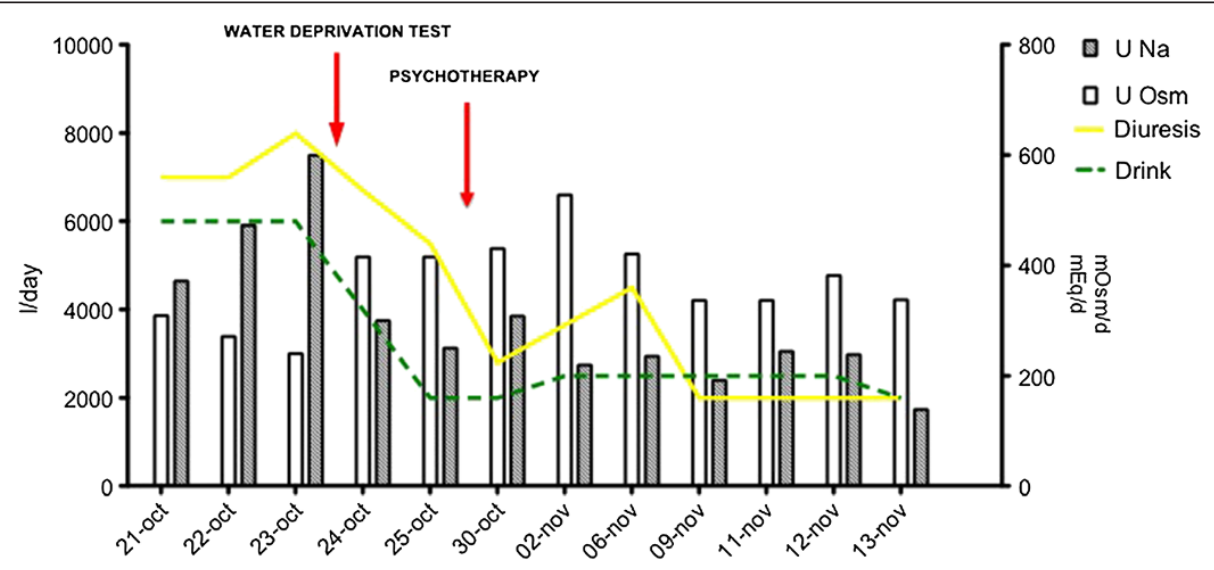

Figure 2 Time trend of clinical and laboratory parameters during the hospitalization. Before the water deprivation test the patient declared a daily water intake of about $1 \mathrm{~L}$, but after the beginning of psychotherapy he admitted to have ingested about $6 \mathrm{~L}$ of liquids per day. Abbreviations are: Uosm = urinary osmolarity, UNa = urinary sodium. 
Table 1 Differential diagnosis of hyponatremia

\begin{tabular}{|c|c|c|c|c|c|c|}
\hline \multicolumn{7}{|c|}{ Hyponatremia } \\
\hline \multirow[b]{2}{*}{ TBW } & \multirow{2}{*}{$\begin{array}{c}\text { Hypervolemic } \\
++\end{array}$} & \multicolumn{3}{|c|}{ Euvolemic } & \multicolumn{2}{|c|}{ Hypovolemic } \\
\hline & & + & + & + & - & - \\
\hline $\mathrm{TBNa}$ & + & $\mathrm{N}$ & $\mathrm{N}$ & $\mathrm{N}$ & - & - \\
\hline Urine $\mathrm{Na}$ & - & + & $\mathrm{N} /+$ & - & - & - \\
\hline Urine Osm & + & + & + & - & + & + \\
\hline Edema & + & - & - & - & - & - \\
\hline BP & - & $\mathrm{N}$ & N & $\mathrm{N}$ & - & - \\
\hline Diuresis & $-/ N$ & $-/ N$ & N & + & - & + \\
\hline \multirow[t]{5}{*}{ Possible diagnoses } & $\mathrm{CHF}$ & SIAD & Drugs & Primary Polydipsia & NON renal Losses: & Renal Losses: \\
\hline & Cirrhosis & & Nausea & & & Diuretics \\
\hline & Nephrotic Syn. & & Addison & & Vomiting & C/RSWS \\
\hline & & & & & Diarrhea & \\
\hline & & & & & Sweating & \\
\hline
\end{tabular}

TBW: Total Body Water, TBNa: Total Body Sodium, BP: Blood Pressure, CHF: Chronic Heart Failure,

SIAD: Syndrome of Inappropriate Antidiuresis, C/RSWS: Cerebral Renal Salt Wasting Syndrome. N: Normal, +:elevated, -: reduced.

condition that we had to face. Owing to the simultaneous presence of metabolic alkalosis and considering the relationship between $\mathrm{K}$ and $\mathrm{H}$ ions, it was difficult to determine which was the main culprit.

The high bicarbonate levels could be explained by the severe ECV depletion and the subsequent massive activation of renin angiotensin aldosterone system (RAAS), resulting in the override of the Tmax of proximal tubular bicarbonate reabsorption and the impossibility to excrete the bicarbonate excess [14].

Besides to result from RAAS activation, this marked hypokalemia was probably associated also with the high urinary flux, related to polyuria. However, it has to remark that hypokalemia could itself hold polyuria, causing both increased thirst and mild nephrogenic DI [15].

Actually, the most challenging issue of this clinical case was the explanation of the marked polyuria in such a depleted patient. Polyuria is defined either on a urine flow higher than $31 /$ day or on the inappropriateness of the urine flow in relation to ECV or natremia [16]. An easy classification of polyuria could be based on Uosm, which is useful to discriminate between the differences in water and solute diuresis. A Uosm $<150 \mathrm{mOsm} / \mathrm{Kg}$ indicates an almost "pure" water-diuresis, a Uosm $>300 \mathrm{mOsm} / \mathrm{Kg}$ suggests a "pure" solute diuresis, while a Uosm between 150 and $300 \mathrm{mOsm} /$ $\mathrm{Kg}$ (the so-called "mixed" diuresis) needs a closer examination [17]. The possible osmotic role of glucose and urea is easily checked by their quantification in the urine. Instead, in the case of an electrolyte driven diuresis, the measurement of Urinary Anion Gap (UAG: i.e. urinary $\mathrm{Na}+\mathrm{K}-\mathrm{Cl}), \mathrm{pH}$ and urinary $\mathrm{Na}(\mathrm{U} \mathrm{Na})$ are necessary. If $\mathrm{UAG}<70 \mathrm{mEq} / \mathrm{l}$ and $\mathrm{U} \mathrm{Na}>250 \mathrm{mmol} / 24 \mathrm{~h}$, as in our case, a sodium chloride diuresis is confirmed [18].
However, a mixed diuresis is composed also by a free-water part that could be ascribed either to DI or to primary polydipsia [19]. In our case, since imaging bore out the hypothesis of DI, we performed a water deprivation test to confirm this diagnosis. Surprisingly, the deprivation test showed a preserved urine concentration ability, which suggested a diagnosis of primary polydipsia. After an accurate psychological evaluation this condition was attributed to a severe depression caused by the long hospitalization. The fact that psychotherapy rapidly improved patient general conditions provided a further confirmation of our diagnosis.

Interestingly, this condition was also consistent with the contemporary presence of hyponatremia, which, at least in part, could have been caused by polydipsia.

The correct diagnosis was followed by a significant reduction of water intake, thus allowing an adjustment of $\mathrm{NaCl}$ supplementation to urinary losses and the achievement of a good hydro-electrolyte balance, which persisted during the time.

In conclusion, the most challenging aspect of this clinical report was the presence of a pool of findings (hyponatremia, hypokalemia and polyuria in a markedly depleted patient), explained by the coexistence of different and often contradictory conditions. An erroneous therapy, as a consequence of an inadequate comprehension of the underlying pathogenetic mechanisms, could have further worsened the already frail clinical setting. A step-by-step and schematic evaluation of all clinical and laboratory signs is necessary to adequately recognize and treat hydroelectrolyte disorders, helping to solve also the most complex clinical problems [20]. 


\section{Consent}

Written informed consent was obtained from the patient for publication of this Case report and any accompanying images. A copy of the written consent is available for review by the Editor of this journal.

\section{Abbreviations}

C/RSWS: Cerebral/renal salt wasting syndrome; DI: Diabetes insipidus;

ECV: Extracellular volume; NMR: Nuclear magnetic resonance;

SAH: Subarachnoid haemorrhage; SIAD: Syndrome of inappropriate antidiuresis; RAAS: Renin angiotensin aldosterone system; TBW: Total body water; UAG: Urinary anion gap; U Na: Urinary sodium.

\section{Competing interests}

Authors declare no financial or non-financial interests to disclose.

\section{Authors' contributions}

$V C$, PE have been involved in drafting the manuscript analysis and interpretation of data; CR, FB, TV, EFP, SB have made contributions to acquisition of data; MG, TR revising it critically for important intellectual content; ADC has given final approval of the version to be published. All authors read and approved the final manuscript.

\section{Acknowledgements}

We thank our colleagues of the First Dept of Anesthesia and Intensive Care and of the Dept of Infectious Disease of Fondazione IRCCS Policlinico San Matteo of Pavia, who provided us data and information on patient clinical history. Authors did not receive any funding for the present paper.

\section{Author details}

${ }^{1}$ Unit of Nephrology, Dialysis and Transplantation, Fondazione IRCCS Policlinico San Matteo and University of Pavia, Piazzale Golgi 19, 27100 Pavia, Italy. ${ }^{2}$ First Department of Anesthesia and Intensive Care, Fondazione IRCCS Policlinico San Matteo and University of Pavia, Pavia, Italy.

Received: 11 April 2013 Accepted: 8 July 2013

Published: 10 July 2013

\section{References}

1. Ayus JC, Arieff Al: Pathogenesis and prevention of hyponatremic encephalopathy. Endocrinol Metab Clin North Am 1993, 22(2):425-446.

2. Chawla A, Sterns RH, Nigwekar SU, Cappuccio JD: Mortality and serum sodium: do patients die from or with hyponatremia? Clin J Am SoC Nephrol 2011, 6(5):960-965.

3. Schrier RW: Body water homeostasis: clinical disorders of urinary dilution and concentration. J Am Soc Nephrol 2006, 17:1820-1832.

4. Adrogué HJ, Madias NE: Hyponatremia. N Engl J Med 2000, 342(21):1581-1589.

5. Sherlock M, O'Sullivan E, Agha A, et al: Incidence and pathophysiology of severe hyponatraemia in neurosurgical patients. Postgrad Med J 2009, 85(1002):171-175.

6. Thompson C, Berl T, Tejedor A, Johannsson G: Differential diagnosis of hyponatraemia. Best Pract Res Clin Endocrinol Metab 2012, 26(Suppl 1):S7-S15.

7. Upadhyay UM, Gormley WB: Etiology and management of hyponatremia in neurosurgical patients. J Intensive Care Med 2012, 27(3):139-144.

8. Bartter FC, Schwartz WB: The syndrome of inappropriate secretion of antidiuretic hormone. Am J Med 1967, 42(5):790-806.

9. Esposito P, Piotti G, Bianzina S, Malul Y, Dal Canton A: The syndrome of inappropriate antidiuresis: pathophysiology, clinical management and new therapeutic options. Nephron Clin Pract 2011, 119(1):c62-c73.

10. Cerdà-Esteve M, Cuadrado-Godia E, Chillaron JJ, et al: Cerebral salt wasting syndrome: review. Eur J Intern Med 2008, 19(4):249-254.

11. Maesaka JK, Imbriano LJ, Ali NM, llamathi E: Is it cerebral or renal salt wasting? Kidney Int 2009, 76(9):934-938.

12. Yee AH, Burns JD, Wijdicks EF: Cerebral salt wasting: pathophysiology, diagnosis, and treatment. Neurosurg Clin N Am 2010, 21(2):339-352.

13. Thornton SL, Resch DS: SIADH associated with sertraline therapy. Am J Psychiatry 1995, 152(5):809.

14. Sabatini S, Kurtzman NA: The maintenance of metabolic alkalosis: factors which decrease bicarbonate excretion. Kidney Int 1984, 25(2):357-361.
15. Weiner ID, Wingo CS: Hypokalemia-consequences, causes, and correction. J Am Soc Nephrol 1997, 8(7):1179-1188.

16. Leung AK, Robson WL, Halperin ML: Polyuria in childhood. Clin Pediatr (Phila) 1991, 30(11):634-640.

17. Kamel KS, Ethier JH, Richardson RM, Bear RA, Halperin ML: Urine electrolytes and osmolality: when and how to use them. Am J Nephrol 1990, 10(2):89-102.

18. Oster JR, Singer I, Thatte L, Grant-Taylor I, Diego JM: The polyuria of solute diuresis. Arch Intern Med 1997, 157(7):721-729.

19. Edoute Y, Davids MR, Johnston C, Halperin ML: An integrative physiological approach to polyuria and hyponatraemia: a 'double-take' on the diagnosis and therapy in a patient with schizophrenia. QJM 2003, 96(7):531-540

20. Laredo S, Yuen K, Sonnenberg B, Halperin ML: Coexistence of central diabetes insipidus and salt wasting: the difficulties in diagnosis, changes in natremia, and treatment. J Am Soc Nephrol 1996, 7(12):2527-2532.

doi:10.1186/1471-2369-14-140

Cite this article as: Corradetti et al:: Multiple electrolyte disorders in a neurosurgical patient: solving the rebus. BMC Nephrology 2013 14:140.

\section{Submit your next manuscript to BioMed Central and take full advantage of:}

- Convenient online submission

- Thorough peer review

- No space constraints or color figure charges

- Immediate publication on acceptance

- Inclusion in PubMed, CAS, Scopus and Google Scholar

- Research which is freely available for redistribution 